\title{
"The Impact of the National Pension Fund on the Suitability of Elderly Pensions in Thailand"
}

\author{
by \\ Wade D. Pfau \\ National Graduate Institute for Policy Studies (GRIPS) \\ 7-22-1 Roppongi, Minato-ku, Tokyo 106-8677 Japan \\ (wpfau@grips.ac.jp) \\ and \\ Vararat Atisophon \\ National Graduate Institute for Policy Studies (GRIPS) \\ 7-22-1 Roppongi, Minato-ku, Tokyo 106-8677 Japan
}

August 2008

\begin{abstract}
This study combines a traditional hypothetical worker approach with the techniques of stochastic forecasting in order to provide a better sense about the suitability of the pension system for formal sector private workers in Thailand. With regard to the proposed defined-contribution pension, we find that workers with a 40 year career can only expect a median replacement rate of about 13 to 14 percent of their final five years of income. Most of the pension benefits will still likely come from the unsustainable defined-benefit pension system and further reforms will be needed to maintain suitable pensions.
\end{abstract}

Keywords: defined-contribution pension, pension suitability, stochastic forecast, Thailand Journal of Economic Literature Classification Number: H55

Acknowledgements:

We would like to thank Deputy Secretary General Singha Nikornpun and other officials at the Government Pension Fund of Thailand, as well as officials from the Fiscal Policy Office of the Ministry of Finance in Thailand, for their helpful assistance in understanding the pension reform proposals being discussed in connection with the National Pension Fund. Also, we gratefully acknowledge the comments and suggestions of participants at the $6^{\text {th }}$ Meeting on Social Security and Complementary Pensions Systems in Lisbon, Portugal, the Alternative Investments Asia meeting in Hong Kong, and at an IMF Asia-Pacific Office seminar. Nonetheless, any errors remain our own. 


\section{INTRODUCTION}

In Thailand, policymakers are strongly considering proposals to introduce a mandatory defined-contribution pension system known as the National Pension Fund (NPF) for private workers in as soon as 2009 as a supplement to the existing defined-benefit pension system. ${ }^{1}$ The goal is to improve the suitability of Thai pensions without further jeopardizing the sustainability of the existing system. Actually, Thailand is just one of many countries in the process of reforming the pension system to better cope with the challenges of an aging population. Reform is needed to ensure that the pension system will be suitable, in terms of providing the elderly with adequate pensions, and sustainable, in terms of ensuring that enough funds flow into the pension system to cover benefit payments and other expenses. In this paper, we focus on the issue of suitability for the Thai pension system with regard to Thailand's formal sector workers.

Now is a particularly important time to focus on pension reform in Thailand. The existing system is still quite new, coverage remains low, and there is still time to make reforms in response to important demographic and economic adjustments without being overburdened by existing unfunded liabilities. Regarding the demographic situation, essentially, declining fertility and mortality rates are leading to an increasingly aging population in Thailand that will place further pressures on the pension system. According to the United Nations Population Division (2004), in the 1950s and 1960s, a woman could expect to bear at least 6 children during her lifetime. Since the 1970s, the fertility rate has experienced dramatic decline, and already by the late 1990s it was settling below the population replacement rate of about 2.1. Nonetheless, the Thai population will continue to grow on account of the improvements in mortality rates brought about by advances in medicine, nutrition, and hygiene. According to the UN, men and women in the 1950 s and 1960 s could expect to live to ages 49.8 and 54.3, respectively. Already, by around 2000, these numbers had increased to about 66 for men and 73 for women, and the UN projects further increases in the coming years. The old-age dependency ratio, which shows the number of people aged 65 and older to people aged 15 to 64, quantifies how the population is aging. At present, the old-age dependency ratio is around 10 percent, meaning that there are 10 people of working age for every elderly person. But by 2025, UN demographers expect the elderly dependency ratio to increase to 20 percent, and by 2050, the dependency ratio could be as high as 35 percent. In this case, there will only be three people of working age for every elderly person.

Beyond these demographic trends, an additional concern for elderly well-being relates to changes in elderly living arrangements. Traditionally, Thai families were extended families, in which family members helped to take care of one another. Elderly family members could typically rely on their extended family for housing, financial support, and other care. The

\footnotetext{
${ }^{1}$ The NPF was originally planned to begin on January 1, 2007 (Chaiyasoot, 2005; Chantanusornsiri, 2006a). The proposal is mainly waiting for parliamentary approval, but the turbulent political situation in Thailand has led to its delay. Currently, the Ministry of Finance plans to introduce the NPF in 2009 once parliamentary approval can be obtained (Chaitrong, 2008). For this paper, we will assume a start date of January 1, 2009, though this may yet prove to be too soon, depending on political circumstances.
} 
importance of this support is such that the World Bank revised their pension framework to include it as the fourth pillar in Holzmann and Hinz (2005). However, rapid economic development in Thailand is changing the structure of families, and elderly people may increasingly find few relatives living close by, as is explained in Ryansakul (2000). As the elderly are expected to become increasingly self-reliant, maintaining a suitable living standard will become difficult without access to a decent pension. These issues altogether raise concerns about the ability of elderly people to maintain an appropriate standard of living and also the ability of the government to arrange support.

As indicated, Thailand is not alone in experiencing challenges to finance the pensions of rapidly aging populations. Changing demographic conditions have been playing havoc on the public pension systems of countries both rich and poor. Traditionally, countries tended to rely on defined-benefit pay-as-you-go pension systems which allowed them to provide pensions to their current elderly using the contributions of the current workforce. These systems tend to work so long as the growth rates of contributors and their productivity exceeds the growth of pensioners. Worldwide, though, reduced fertility rates and increasing longevity are making such systems unsustainable in the sense that promised pension payments to the increasing elderly populations will exceed worker contributions. In response, a number of countries are increasingly shifting their public pension systems toward defined-contribution pensions, in which the pension provider does not make a promise about benefit levels, but rather the pension amount is determined by the performance of the assets accumulated in the pension account. Whitehouse (2007) indicates that defined-contribution pensions have become very common in Latin America, the Caribbean, Eastern Europe, and Central Asia. It is in this direction that Thailand is moving with the proposed National Pension Fund.

In Thailand's case as well, increasing the funding for the pension system can provide an important source of savings for the country. Though some savings will be moved from existing voluntary pension funds to the NPF, the NPF should still result in increased savings for the Thai economy. Chaiyasoot (2005) indicates that the need for increased savings to support various large-scale investment projects is an important justification for introducing the NPF.

We must also consider the economics of pension reform and pension suitability. Especially with regard to the proposed defined-contribution pension system, Thai workers will invest their savings in risky financial assets which may experience capital gains or capital losses from year to year. Forecasting pension suitability thus requires long-term forecasts of economic and financial performance. Traditionally, pension forecasts have been created with a deterministic, scenario-based forecasting approach. This often involves three alternative scenarios: a low-cost (“optimistic”) alternative, an intermediate-cost ("best guess") alternative, and a high-cost ("pessimistic”) alternative, such as is done in the Asian Development Bank Consultant's Report (2000) for Thailand. Each of these scenarios combines a set of assumptions about the future course of economy, but this type of deterministic approach does not provide the reader with any sense of the likelihood with which these future scenarios may occur, and it 
combines the assumptions in overly rigid ways, and hence it does not provide a sense of the future risks.

The expansion of defined-contribution pension systems that include investments in equities and fixed income securities in recent years makes reliance on the deterministic approach all the more troubling. This is because the volatility of actual investment returns may not be represented very well by a deterministic approach, and a proper investigation of investment returns must consider more than just the expected value of the outcome in order to properly account for the risks. Unlike deterministic forecasts, stochastic forecasts can be used to estimate a probability distribution for outcome measures, which can be used to understand the likelihood of various outcomes and to better capture the extent of volatility in the performance measures. As such, we will create stochastic forecasts for the Thai economy in order to obtain a probability distribution for the future pension benefits available to Thai workers. Our research approach is motivated by the work of Ronald Lee and others, particularly Lee and Tuljapurkar (1998), and Lee, Anderson, and Tuljapurkar (2003). Other examples of this stochastic forecasting approach include Harris, Sabelhaus, and Simpson (2005), and Feldstein and Ranguelova (2001).

Regarding for whom we will simulate these future pensions, we will use hypothetical Thai workers retiring between 2014 and 2060 who earn some fraction of the economy-wide average wages throughout their working careers. These dates are chosen because while accumulated savings will still be small in 2014, this is the first year in which workers will be eligible for annuities from Thailand's existing defined-benefit pension, and by 2060 we have reached a steady state in which workers are able to contribute to their defined-contribution pension at the maximum contribution rate for their full career. We will define their years of birth, age that work begins, age of retirement, and lifetime earnings level and pattern. Naturally, such workers are not representative of everyone, but they will provide a framework for comparing how pension reform could affect the suitability of pensions. This approach is often used to provide analysis of social security reform issues, including whether participants will get their "money's worth" from their contributions to defined-benefit systems, how much benefits participants can expect from defined-contribution pensions, and how a defined-benefit pension system redistributes income between participants, both within a cohort and across cohorts.

Recent studies using hypothetical workers in this way include Steurle and Bakija (1994), Nichols, Clingman, and Glanz (2001), Burtless (2002), Pfau (2003), and Shiller (2005).

This study combines the traditional hypothetical worker approach with the techniques of stochastic forecasting, in order to provide a better sense about the suitability of the pension system for formal sector private workers in Thailand. While this technique is relatively new, it can provide important insights about pension reforms that include volatile investment choices. The use of hypothetical workers to study pension reform has a lengthy history, as while such workers may not represent the specific situation for any particular person, they can provide reasonable examples to clarify how the pension system will function in practice for representative individuals. But the use of hypothetical workers to study pension reform is usually undertaken by using deterministic forecasts, often with several different scenarios, for the 
future course of the economy. This approach is particularly hazardous for considering pension reforms that include investment in equities and fixed-income securities, because the average historical returns for various investments do not directly reflect their underlying risk. Burtless (2002) and Shiller (2005) respond to this problem by using successive historical periods and by bootstrapping the historical data to represent the potential variability in outcomes, and our paper contributes to this literature by extending to the use of stochastic forecasts for the economy in order to obtain a probability distribution over the likely effects of pension reform.

With the creation of the National Pension Fund, Thai pensions will include a large and important role for defined-contribution benefits, which shift demographic and economic risks from the government to individuals. This creates concern about the potential performance of the underlying investments. Historically, the Thai stock market has been very volatile, and even if savings in the stock market could produce higher benefits on average for retirees, there is no promise of higher benefits for any given individual. The question remains about how much risk Thai workers would face with the new National Pension Fund. We seek to examine this important issue, to determine what level of pension benefits could be expected from the definedbenefit and defined-contribution portions of the mandatory pensions. We find that the combined pension may be suitable, but it is not sustainable in its current form. Most of the pension benefits will come from the defined-benefit portion of the pension system, and our results indicate that this part of the pension system is not sustainable, as contributions will fall short of promised benefits. Meanwhile, once the defined-contribution part of the pension matures, workers should only expect an average income replacement rate of 13 to 14 percent, which while sustainable is far from suitable. Thus, while creating the National Pension Fund is a step in the right direction, further reforms will be needed to ensure that suitable and sustainable pensions are available for the Thai population. To obtain these results, the paper will proceed as follows. In the next section, we consider the details of Thailand's pension system. Then, we explain the methodology and application of our stochastic hypothetical worker model to the situation in Thailand. This is followed by our results, and we finish with some concluding observations and policy recommendations.

\section{THE PENSION SYSTEM IN THAILAND}

This paper focuses on the mandatory, contributory public pension system for formal sector private workers in Thailand, which includes the first and second pillars of the World Bank framework described in Holzmann and Hinz (2005). ${ }^{2}$ The first pillar is a mandatory contributory defined-benefit (DB) system linked to earnings, which seeks to replace some portion of a worker's income at retirement. In Thailand, this first pillar is the Old-Age Pension Fund (OAPF), which operates as part of the Social Security Fund. The second pillar of the World Bank

\footnotetext{
${ }^{2}$ Holzmann and Hinz (2005) update the World Bank framework to include 5 pillars. The pillars not addressed in this paper include Pillar 0 , which is a non-contributory pension provided to elderly people by the government that may either be universal or means-tested, Pillar 3, which are voluntary arrangements whereby workers save additional funds for retirement either by themselves or through an employer, and Pillar 4, which is the informal support provided to the elderly within their family. In Thailand, Pillar 3 includes the Provident Fund (established in 1987) and the Retirement Mutual Fund (established in 2001).
} 
approach is a mandatory defined-contribution (DC) system that acts as a savings account for participants. Workers place a portion of their income into the account which is vested into a range of financial assets, and the total assets available at retirement will depend on the performance of the underlying portfolio. In Thailand, this is expected to be part of the reforms to create the National Pension Fund (NPF), and it is expected to begin operations in 2009. ${ }^{3}$

With regard to Thailand's first pillar for private workers, the Social Security Fund began collecting contributions for the OAPF starting in 1999, and it will begin making annuity payments to retirees with at least 15 years of contributions in $2014 .^{4}$ Funding obligations for the Social Security Fund are split between employers, employees, and general government revenues, and funds are allocated among three benefits categories. The combined total tax rate since 2004 for the Social Security Fund is 12.75 percent, and the portion of this dedicated for old-age pensions and child allowances is 7 percent. This amount for the OAPF is split as 3 percent from employers, 3 percent from employees, and 1 percent from general government revenues. The minimum earnings needed to contribute are 1,650 baht per month, and the maximum taxable earnings are 15,000 baht per month. In addition, these contributions are tax deductible and the benefits received are tax exempt. ${ }^{5}$

The old-age benefits provided by the OAPF follow a DB formula. Contributors who retire with more than one year but less than 15 years of participation will receive a lump-sum payment equal the contributions of the employee and employer plus interest at the rate set by the Social Security Office in each year. ${ }^{6}$ If someone contributes for less than 12 months, their employee contributions will be returned. The formula to calculate benefits for those with at least 15 years of contributions is:

$$
B E N E F I T=S A L A R Y \times \frac{(1.5 x-2.5)}{100}
$$

where BENEFIT is the total monthly benefit expressed as a percentage of $S A L A R Y$, which is the average monthly salary from the last 60 months (5 years) of employment. Additionally, $x$ represents the number of years of contribution to the pension system. Thus, someone with 15 years of contributions will have a replacement rate of 20 percent, while 30 years provides 42.5 percent, and 40 years provides a replacement rate of 57.5 percent. $^{7}$

\footnotetext{
${ }^{3}$ The NPF will likely encompass the various existing pensions in Thailand while incorporating a new mandatory defined-contribution pension as well. To simplify the language though, we will sometimes refer to the new DC pension as the NPF, even though it is only expected to be a part of the NPF.

${ }^{4}$ Our discussion of the OAPF is based on a variety of sources, including the Social Security Office (2005), Asian Development Bank Consultant's Report (2000), Kanjanaphoomin (2000), Pai (2006), Ryansakul (2000), and Kesornsutjarit (2000).

${ }^{5}$ It must be made clear that the OAPF and NPF will only cover Thailand's formal sector labor force, which is currently about one-third of the actual labor force.

${ }^{6}$ From 1999 to 2005, the annual interest rates were 2.4, 3.7, 4.2, 4.3, 6.5, 2.0, and 2.0, respectively.

${ }^{7}$ This benefit formula represents a recent legislative change to make more generous benefits. The formula is described in the Social Security Office's 2005 Annual Report. Previously, as is cited by most literature about the Thai pension system, the benefit formula was, BENEFIT $=$ SALARY $* x / 100$, with the terms defined the same as in the text and $x$ must be at least 15 years.
} 
The OAPF is operated on a pay-as-you-go basis, though it is currently developing some pre-funding prior to the introduction of benefit payments, and there is no guarantee that the fund will be sustainable, in terms of the contributions entering the fund being adequate to pay all of the promised benefits. This is especially the case with the expected aging of the Thai population. With this DB approach, the government bears the risk of the future economic and demographic changes, as it will be obligated to pay benefits according to its formulas regardless of what happens to future contribution levels, or to the returns on its underlying assets. Thailand is just one of many countries now pursuing alternative funding strategies to relieve pressures on the government to provide pension benefits. It is in this regard that the National Pension Fund is being introduced to Thailand.

In Thailand, the second pillar mandatory DC pension system is expected to begin operation in 2009 as a part of the National Pension Fund (NPF) reforms. Since it does not yet formally exist and the Thai government has not finalized the details, we must speculate about how it is likely to operate based on press reports and interviews with government officials about their intentions. First, the fund will either be centralized or decentralized. If centralized, the likely possibility is that the NPF will be modeled after the Government Pension Fund (GPF), which is the existing second pillar pension for civil servants and military officers. ${ }^{8}$ In this case, Thailand will essentially expand the GPF to apply to all formal sector workers. Otherwise, if the fund is decentralized, it will likely be modeled after the voluntary Provident Funds, which are decentralized with many fund managers, making various investment choices possible for participants. Actually, since we directly test the implications of different asset allocations, the details of how they will be managed are not important for our results, and our findings are applicable for both of these possible systems.

The NPF will likely be operated on a DC basis from both employees and employers. Starting in 2009, we assume that the employee and employer will each contribute 3 percent of the worker's wages to the DC pension. In 2012 and 2017, we increase these amounts to 4 percent and 6 percent, respectively. Chantanusornsiri (2006b) mentions that such contribution rate increases will be likely. The formal retirement age for the NPF is proposed to be 60 years old. However, early retirement at 55 years old may be possible for workers in some physically demanding industries. Formal sector workers will contribute to individual accounts that are vested in a variety of financial assets and will be converted into a lump-sum payment consisting of contributions and capital gains (or losses) at the time of retirement. Then, rules will probably require the conversion of the lump-sum payment into a lifetime annuity, if such annuity markets are able to develop in the future. Unlike a DB system, a particular benefit level is not guaranteed, unless the government is to provide some minimum guarantee funded through general revenues in the event of unfortunate investment performance. Benefit amounts will largely depend on how successful the worker's portfolio investments have been.

\section{// Table 1 About Here //}

\footnotetext{
${ }^{8}$ Funke and Stadtmann (2004) provide an excellent overview of the Government Pension Fund.
} 
As such, asset allocation decisions for the NPF are very important, and will certainly be the subject of continued debate in Thailand. We assume that the NPF's asset allocation will be modeled after the existing GPF. The trend in asset allocation for this fund is shown in Table 1. This fund has been undergoing rapid changes in asset allocation, including the recent introduction of foreign assets. The portion dedicated to Thai fixed income assets has always been the highest, ranging from 88 percent of the allocation in 2001 to 68 percent in 2005. Thai equities provide the next largest category, and in 2003 and 2004 they represented 15 percent of the assets. Other categories include Thai property, alternative assets (mainly private equity), global fixed income assets, and global equities. While the GPF is a single fund, it is possible that the NPF could introduce investment choices, such as in accordance with the Asian Development Bank (2000) recommendation of three choices for participants: aggressive, balanced, and conservative. These possibilities will be illustrated with the range of scenarios we consider, though our baseline portfolio will be 15 percent equities and 85 percent fixed income, which is an asset allocation most similar to the GPF in 2002 and 2003.

\section{METHODOLOGY FOR STOCHASTIC HYPOTHETICAL WORKERS MODEL}

Our methodology includes two steps: first we develop long-term stochastic forecasts for the Thai economy, and then we apply these forecasts to the pre-defined career paths of a variety of hypothetical workers. We will discuss these matters in turn.

\section{The Application of Stochastic Forecasts to Study Pension Reform in Thailand}

To examine the suitability of pensions in Thailand, we will create stochastic forecasts for four key economic variables. These four variables include the Headline Consumer Price Index (Headline CPI), the one-year fixed bank deposit rate, the Stock Exchange Index (SET) for Thailand, and the average wage level. Data for the first three variables come from the Bank of Thailand, while wage data is from Thailand's General Statistics Office. The one-year fixed deposit rate is our proxy for the returns to less risky fixed income securities available to Thai workers ${ }^{9}$, and the SET index is our proxy for the returns Thai workers can experience by investing in equities. For Thailand, historical data are available on an annualized basis for 1979 to 2005, except average wages. Average wages start from 1989 and annual average wages are calculated from monthly data. For one-year fixed deposit rates, in some years a range of rates is provided, and in these cases we select the middle value of the range.

\section{// Table 2 About Here //}

For these variables, the nominal growth rates and real growth rates are computed and shown in Table 2. The analysis here will be conducted in real terms. Deserving of particular mention is the Thai stock market. Between 1979 and 2005, the average real return on the Thai SET index was 7.32 percent per year. However, the Thai stock index has shown remarkable volatility during this time period, declining by as much as 57.56 percent in 1997, and rising by as much as 112.77 percent in 2003, in real terms. The standard deviation of the returns during this

\footnotetext{
${ }^{9}$ We choose the one-year fixed deposit rate for several reasons. Most importantly, it is used as the benchmark to compare returns from the GPF, and data for longer-term bonds, such as three years or ten year government bonds, are available only since 1996.
} 
time period was 44.54 percent, so that the geometric real return to the Thai stock index was actually -0.89 percent during these years, representing a loss of purchasing power. We make the stochastic forecasts using the historical returns and standard deviations in Table 2, under the assumption that these variables have growth factors that are lognormal and are independently and identically distributed in accordance with their historical characteristics. We create 1,000 stochastic simulations of the four variables through 2060, based on this historical data.

\section{Methodology for Hypothetical Workers and their Pensions}

We will apply these stochastic forecasts to hypothetical workers in order to study pension suitability. Actually, defining hypothetical workers in Thailand is generally easier than for other countries because of two reasons: Thailand does not have a spousal retirement benefit so that it makes no difference whether a worker is married, and there is no progressive benefit formula to redistribute wealth through the pension system, such that the actual level of earnings (low, medium, or high) has little impact on measurements comparing pension benefits relative to income and contributions. Thus, we only consider average wage workers. ${ }^{10}$ We appeal to the hypothetical worker approach because of difficulties in obtaining data on the lifetime earnings of Thai workers. We will indicate the direction of any bias created by our assumptions.

We consider workers who retire in years ranging from 2014 to 2060. For each worker, we assume that employment begins on the $20^{\text {th }}$ birthday and lasts continuously until retirement. We assume that the retirement age will be the $60^{\text {th }}$ birthday, and so each worker has a 40 year continuous work history. ${ }^{11}$ We will only use average wage workers, who are assumed to earn wages equal to the average wage in Thailand for each year of their careers. This pattern will produce a trend of increasing real wages throughout one's career on account of the upward trend of real wages over time.

Furthermore, we do not use a steady average earnings history, where wages at each age are defined as a constant proportion of average wages. This has been a deficiency of a number of previous studies. Rather, we use the 2002 Socioeconomic Survey of Thailand to find the pattern between age and earnings level at a given time, which is illustrated in Figure 1. In 2002, young workers tend to earn substantially lower wages, and it is at about age 40 that wages begin to exceed the economy wide average. We assume this pattern extends into the future and apply it to obtain average wages by age. In comparing the scaled earnings history to the steady earnings counterpart, the assets accumulated in the DC account will tend to be less, because contributions are shifted from early to late in one's career, and it is contributions at young ages that would have experienced the most compounded growth before retirement. The scaled earnings history will also reduce our outcome measures, which compare pension benefits to the last five years of

\footnotetext{
${ }^{10}$ We ignore the issue of minimum and maximum salaries with which participants pay contributions, because it is not clear how these will be adjusted in the future to account for price and/or wage growth. For average wage workers, these constraints should not be binding, but this is the only factor that could create differences in the ratios between benefits and salary for participants based on their salary levels. ${ }^{11}$ Currently, the retirement age for the OAPF is 55, but it will probably be 60 for the NPF, and it is reasonable to expect that the OAPF retirement age will be increased to 60 as well to correspond with the NPF (Chantanusornsiri, 2006a and 2006b).
} 
salary, in accordance with how benefits are calculated. This is because, as Figure 1 shows, salary between ages 55 and 59 (the final five working years) is higher than the lifetime average.

\section{// Figure 1 About Here //}

The reason that we do not consider people retiring before 2014 is simply because the SSF did not begin to collect contributions for old age pensions until 1999 and one must contribute for 180 months (15 years) before becoming eligible for an annuity. The range of retirement years ends in 2060, because by then (in 2057, to be precise) workers have participated with the highest contribution rates for 40 years under both systems and so a steady state is reached.

We will calculate pensions coming from both of the mandatory parts of the Thai pension system, the OAPF and the NPF. For both pensions, we will allocate the entire payroll tax contribution to the worker, even though the legal incidence of the payroll tax is shared between the worker, the employer, and the government. Studies of wage elasticity in the United States justify this assumption; employers generally reduce wages by the amount of their payroll tax contribution. Also, it is not meaningful to say that the government contributes to the pension, since these contributions ultimately come from taxes, except that this design may lead to redistribution from those not covered by the pension system to those who are covered. As such, the combined tax rate for the OAPF is 3 percent in 1999, 5 percent from 2000 to 2002, and 7 percent in 2003 and later. For the DC pension, the combined tax rate is 6 percent from 2009 to 2011, 8 percent from 2012 to 2016, and 12 percent in 2017 and subsequent years. For the OAPF pension, this study will calculate benefits using the new OAPF benefit rule in Equation 1. We do not consider any possible child or survivor benefits from the OAPF, only the retirement pension.

Regarding the DC portion of the NPF, the details of this program have not been finalized, and many important decisions will need to be made. The returns expected to be obtained from the DC accounts are quite sensitive to the assumptions made about asset allocation, the nature of the annuitization process, whether there will be minimum benefit guarantees, and the treatment of account bequests upon death. Policymakers must decide how much freedom Thai people will have to choose their investment portfolios, and whether there will be restrictions on asset classes such as Thai equities, real estate, international assets, and other alternative assets.

First, we consider a worker's NPF account during the accumulation phase. We assume that workers will place their annual contributions into their investment portfolios at the end of each year. The investment portfolios are split between equities (an index of the SET) and bonds (one-year time deposits). Though there is likely to be strict limitations on the amount of stocks than can be owned, we will consider a range of portfolios between 100 percent stocks and 100 percent bonds. Our baseline portfolio is 15 percent equities and 85 percent bonds. We do not consider diversification into foreign assets or into real estate and other alternative assets, though we wish to do this in subsequent research. We further assume that there will be an annual administrative cost of 0.3 percentage points for the individual accounts, which is likely on the low end of possible expenses. All stock dividends and bond interest payments will be reinvested and will be free from income taxes. We will rebalance the investment portfolios at the end of each year, in order to maintain the same asset allocations over time. 
At retirement, decisions must be made about the annuitization process. We assume that all of the accumulated assets will be annuitized. This helps to protect against the risk of outliving one's assets, but it does limit the flexibility for NPF participants about their retirement spending. Annuities are not common at the present in Thailand, but it is reasonable to expect that an annuity market will be able to develop by the time that the NPF matures. We further assume that the annuities will be provided in real terms and fixed, which means that they start at a lower level but enjoy annual cost-of-living adjustments that match the inflation rate. Risk averse individuals are likely to prefer this type of annuity, because it avoids additional risks related to inflation and the investment returns of the annuity assets. We further assume that the overhead costs for purchasing an annuity are 10 percent, and we consider annuities for individuals, rather than joint and survivor annuities for married couples.

Calculating the annuity requires dividing the total assets accumulated at the time of the retirement (less the overhead costs) by the actuarial present value (APV) of each baht of savings. This value accounts for the probability of survivorship for each age beyond retirement, as well as an assumed interest rate for the returns on remaining annuitized assets. Regarding survivorship probabilities, our mortality data by age and gender comes from two sources. We adjust the byage pattern in the World Health Organization life table for 1999, so that they match the life expectancies between 1950 and 2050 in the medium projections of the UN Population Division (2004). When calculating annuities, we use unisex survivor probabilities, as may be required by law, and so we weigh mortality rates by the numbers of men and women in the population at each age. As for the expected return on remaining annuitized assets, with the real fixed annuity we assume a rather conservative portfolio of 100 percent bonds for the remaining assets. The expected real return of this portfolio is equal to the mean of the forecasted "historical data" at the date of retirement for each stochastic simulation.

\section{RESULTS}

This study attempts to determine whether the first and second pillars of the proposed National Pension Fund in Thailand can be expected to provide a reasonably adequate income for the retirees. According to Chaiyasoot (2005), a suitable level for retirement pensions would be to replace 50 to 60 percent of the last month's salary at retirement. Then, it is a matter of determining whether the pension benefits would be able to replace this much income. In order to examine this issue, we will consider the nest-egg ratio and the replacement rate. As is the case with how the benefits are calculated in Thailand, we define the nest-egg ratio as the ratio of accumulated assets in the DC account at retirement to the average of the last five years of income before retirement. The replacement rate is the percentage of the average income from the last five years of employment that the pension annuity will provide. First, we consider the benefits from the DC pension in terms of the nest-egg ratio (Table 3 and Figure 2) and the replacement rate (Table 4). Our baseline portfolio assumes an allocation of 15 percent equities and 85 percent fixed income assets. The tables also show the results for three other asset allocations (100\% stocks; $50 / 50$ stocks and bonds; $100 \%$ bonds) in order to make further comparisons. Table 5 then considers the combined benefit from the two pillars. 


\section{// Figure 2 About Here //}

Before examining the tables, Figure 2 provides a visual demonstration of the stochastic distribution for the nest-egg ratio available to average wage workers who participate in the NPF starting in 2009 for the baseline asset allocation. The distribution of nest-egg ratios shows an upward trend over time that stabilizes in the mid-2050s. This is a result of the increasing years of contributions since the start date for later retirees. Also, because the contribution rate rises to its maximum of 12 percent of income in 2017, it is only people who retire in 2057 who will have contributed at the maximum rate for their entire 40 year career. Retirees in 2014 contributed a relatively small amount during their 5 years of participation, and thus can be expected to have accumulated savings that is only about half of their average salary during their last five years of employment. The median nest-egg ratio can be expected to rise to about twice the average salary by the late 2020s, and about four times the average salary by the 2040s, with only slight increases after that. The purpose of using stochastic forecasts, though, is to examine the distribution of possible outcomes that workers may expect, and we find evidence of a great deal of diversity in potential outcomes. As we can see in the figure, the distribution is not symmetric, because the lognormal distribution of returns prevents accumulated assets from falling below zero, and it is widely dispersed with a small chance that accumulated assets become very large.

\section{// Table 3 About Here //}

Table 3 shows specific numbers to describe the distribution in Figure 2, and it also provides results for other asset allocations. For the baseline case, in 2050, for example, the median is 4.0 and the 90 percent interval for the nest-egg ratio ranges from 2.6 to 7.02. Because the distribution is not symmetric, the mean performance can be misleadingly large. For the baseline case, Table 3 also shows the probability of obtaining a nest egg larger than 1, 4, and 7, in order to give another interpretation about the variance of results. By the time that the system matures in 2060, workers can expect their nest egg ratio to exceed 4 more than 50 percent of the time, and there is only a 6.3 percent chance to have a nest egg ratio exceeding 7.

One must also recognize that there are two opposing reasons that explain the relative size of the nest-egg ratio. On the one hand, the nest-egg ratio can be small because the returns from the worker's investments are low, and occasionally a worker may see a large drop in the stock market in the final years of their career, leading to a smaller amount of accumulated assets. This is the risk of investing in such assets, particularly in consideration of the large volatility that the Thai stock market has shown in the past. On the other hand, a "good" reason for small nest-egg ratios occurs when workers experience rapid wage growth in the final years of their career. This makes their final earnings much more attractive than the earnings earlier in their careers, which will decrease the value of their nest-egg ratio (since it only considers the final five years of income in the denominator) without necessarily making the worker feel worse with respect to their overall lifetime earnings.

Table 3 also provides the stochastic forecasts for nest-egg ratios assuming several different asset allocations ranging from 100 percent stocks to 100 percent bonds. The main trends are that as the amount of equity increases in the portfolio, the median falls (once the 
portion of equities exceeds 15 to 25 percent), the mean increases, the 90 percent interval widens, and the probabilities of having either a very small or very large nest-egg ratio increase. For example, the portfolio with 100 percent stocks produces for 2060 retirees a median nest-egg ratio of 2.8, while the mean is 8.06 and the 90 percent interval ranges from 0.67 to 27.26. The probabilities tell more of the story, as the probability of producing a nest-egg ratio less than 1 increases from 0 percent to 13.9 percent, but the probability of producing a nest-egg ratio larger than 7 also increases from 6.3 percent to 24.5 percent. Investing in 100 percent stocks produces the best chance for extreme success, but it is also incredibly risky on account of the potential failures. The next portfolio is 50 percent stock and 50 percent bonds, and the results of this portfolio fall somewhere between the baseline and 100 percent stocks. The median performances are quite similar to the baseline portfolio, but the range of outcomes is wider. For example, in 2060 the 90 percent interval ranges from 1.58 to 14.43. Also, the chance of producing a nest-egg ratio less than 1 in 2060 is only 0.3 percent, while the probability of greater than 4 is 51.5 percent, and the probability of greater than 7 is 24.9 percent. Finally, the last portfolio considers 100 percent bonds with no diversification into stocks. This portfolio produces low but stable returns, though ne would require a large degree of risk aversion before preferring this portfolio over the baseline.

More relevant to the case of retirement spending is the replacement rate a worker could expect to receive by converting their accumulated assets into an annuity at retirement. The annuity calculation translates nest-egg ratios into replacement rates using the assumptions for a real fixed annuity as explained in the methodology section. The shape of the replacement rate distributions for the various portfolios follows the same patterns as the nest-egg ratio, re-scaled to show the replacement value of the annuity. Thus, the same discussion about distributions and comparisons between portfolios for nest-egg ratios applies to replacement rates as well.

\section{// Table 4 About Here //}

We find in Table 4 that Thai workers cannot expect large annuities from their savings, as the median annuity amount does not rise above about 14 percent of final salary for any asset allocation, even when the system has fully matured. Even by 2030, the median replacement rates will be below 10 percent. But again, the distribution of replacement rates is quite large. In 2060, the 90 percent interval for the baseline case ranges from 8.71 percent to 23.48 percent. Most workers (87.2 percent) can expect a replacement rate of greater than 10 percent with the baseline distribution, but only 3.3 percent will enjoy a replacement rate above 25 percent. The portfolio with 100 percent stocks is most risky, as only 47.4 percent of participants can expect a replacement rate above 10 percent, but 21.8 percent will see replacement rates above 25 percent. Meanwhile, the portfolio with 100 percent bonds gives about the same chance as the baseline case to have a replacement rate above 10 percent, but almost no chance for a replacement rate above 25 percent.

With the assumptions for the stochastic forecasts based on Thailand's historical period, and especially because the Thai stock market has shown much more volatility than most other countries, it is possible that in the future Thailand's economy will behave differently as it 
becomes more mature and stable. As such, we also consider a second forecast for the Thai stock market, which matches more general historical trends for equity returns throughout the world. This second scenario could either be interpreted as a brighter future in which Thailand's stock market behaves more closely to international trends, or as the investment of its pension assets into global equities. For this scenario, we assume an annually compounded real return to equities of 7 percent, with a standard deviation of 20 percent, which implies an arithmetic real return of 9 percent. In the baseline case, this optimistic assumption still does not have much effect, as the median replacement rate will only increase to about 15 percent once the system matures. As more equities are added to the portfolio, the results will increasingly differ from Table 4, as the overall distribution of replacement rates increases. For instance, in considering a portfolio with 100 percent equities, the median replacement rate for 2060 retirees is 29.78 percent, and the 90 percent interval ranges from 9.86 percent to 108.3 percent. Thus, to the extent that Thailand's economy follows a more stable growth pattern in the future and its stock market follows international trends, we can expect an improvement in median replacement rates, though the improvements will be minor in the baseline case and only become more noticeable when there is a higher allocation for stocks.

Next, Table 5 provides information about the probability distribution for the combined benefit replacement rate of the DB and the DC pensions. This first pillar DB pension from the OAPF is expected to provide generous benefits to participants, especially with the benefit increases legislated in 2005. But the OAPF only began collecting contributions in 1999, and so according to the DB pension formula, those retiring in 2014 will have had 15 years of contributions, and are thus entitled to a replacement rate of 20 percent of their last five years of earnings. In subsequent years, retirees enjoy larger benefits because more years of contributions have been available since 1999. Each year witnesses a growth in the replacement rate of 1.5 percentage points. Thus, for example, between 2030 and 2040, the replacement rate from the OAPF would increase from 44 percent to 57.5 percent. Participants retiring in 2039 and later will have contributed to the OAPF for 40 years, under our assumptions of a continuous work history, which entitles them to a replacement rate of 57.5 percent. There is no stochastic distribution for the replacement rate of the OAPF benefit because it is defined with regard to wages, and the government bears the risk of funding the benefit.

\section{// Table 5 About Here //}

Table 5 shows the overall replacement rate from the two systems, adding the replacement rates just described for the OAPF with the NPF replacement rates found in Table 4. Once the pension system matures and workers are able to contribute to both systems throughout their entire career, the median combined replacement rate in the baseline case will be about 71 percent. Additionally, the $5^{\text {th }}$ percentile will be about 66 percent, and participants can be virtually guaranteed to have replacement rates larger than 60 percent. The same pattern emerges when considering other asset allocations. Contributors with a 100 percent allocation for stocks will have lower median replacement rates, but they can still enjoy an over 90 percent probability of having a replacement rate larger than 60 percent. And because of the large volatility of stocks, 
some workers can enjoy replacement rates in excess of 100 percent. And a conservative portfolio of 100 percent bonds will virtually guarantee replacement rates of over 60 percent and provide a 53.4 percent chance of rates above 70 percent. By international standards as well as by the expectations provided in Chaiyasoot (2005), the combined replacement rate appears suitable, and voluntary savings will remain as an option for people seeking larger retirement incomes. Because the DB pension provides such a large benefit, this may provide a reason for participants to desire riskier asset allocations for their DC pension. At the same time, however, the OAPF can hardly be expected to be sustainable, as will be explained further below, and if OAPF benefits are reduced in the future, then this will have obvious implications for the overall replacement rate.

\section{CONCLUSIONS AND POLICY RECOMMENDATIONS}

We have examined a number of issues related to the suitability of Thailand's mandatory pension systems. We find that pensions will be suitable, though this is mostly because of the generous pensions provided by the defined-benefit OAPF. Once the defined-contribution pension from the NPF matures, workers can only expect an income replacement rate of 13 to 14 percent from it on average, and the remainder is from the DB pension. Thus, these results must be accompanied by a large caveat that deserves particular emphasis. The defined-benefit OAPF pension may not be sustainable. Our analysis shows that when the pension systems mature, the DC pension will collect 12 percent of wages each year while the DB pension collects 7 percent of wages. Nonetheless, the DB pension will provide a replacement rate of 57.5 percent for a 40 year career, while the median replacement rate for any portfolios from the DC pension do not exceed about 14 percent. Thus, it is rather unclear how the OAPF will be able to fund such a large pension.

To be sure, this paper does not complete the story about pension reform in Thailand, because hypothetical workers do not allow us to quantify the size of various population cohorts, and we cannot be sure that the hypothetical workers will represent the actual population of contributors in terms of total years of contributions and pattern and level of earnings. There is still much to be gained from creating a full actuarial model in order to better understand sustainability issues related to the OAPF. Nonetheless, we can observe that there is indeed a large discrepancy between the contributions and benefits of the two systems, and the aging population in Thailand will only serve to compound the funding problems of the OAPF. More work must be done in this regard, in order to provide a complete picture of suitability and sustainability issues.

Aside from the sustainability issue, many policy recommendations for both the OAPF and NPF follow from this work. First, the OAPF pension amount could be calculated based on a longer period of earnings in order to better match average lifetime earnings. On average, workers can obtain higher pensions by basing the amount only on the last five years of earnings, which increases the costs for the government, as the microdata shows that conditional on continuing work, wages do trend upward, at least until age 60. But some people may experience wage reductions late in their careers, which could hurt their pensions. This may also create a 
large disincentive to remain in the labor force, as the prospect of a reduced wage for someone close to retirement could have serious implications for the pension amount from the OAPF.

As for other recommendations, it is questionable about whether the OAPF should include funding from general government resources, as this implies a redistribution of income from the general taxpaying population to the privileged members of the formal labor sector. Additional reforms worthy of consideration include creating a spousal benefit for married workers, creating a progressive benefit formula for the OAPF, increasing the retirement age to at least 60 , and expanding coverage to more workers. Meanwhile, for the defined-contribution pension in the NPF, the main issues revolve around asset allocation. Thai equities have been very volatile, but at the same time, since the DC pension is a relatively small part of the total pension, people may want to take a risk with stocks to have a chance at the possible large upside potential. Also, providing investment choice, creating life-cycle portfolios that allow for greater risk when young, and diversifying into international and alternative assets can play an important part in the further development of the National Pension Fund. Finally, policymakers may wish to further assess the balance between the defined-benefit and defined-contribution systems, to decide on the best allocation of contribution rates between the two systems.

More research is also warranted with respect to the DC aspect of the NPF. It is important to incorporate realistic measures of risk aversion for the Thai population in order to determine an appropriate asset allocation for the DC pensions, particularly if the government chooses a single fund approach that matches the GPF. Additionally, further work is warranted to consider a wider variety of assets for the portfolio, including real estate, private equity, and international investments. In this regard, it is also important to more properly model the correlation between different asset returns, rather than assuming independent distributions. Finally, calibrating the number of years people spend working in the formal sector labor markets would help to better estimate pension amounts for both the DB and DC pensions. 


\section{References}

Asian Development Bank’s Consultant, 2000, Pension Fund Reform: The Case Study of Thailand: Establishing a Multi-Pillar Pension System in Thailand for Reforming and Options for Implementation. The Third APEC Regional Forum on Pension Fund Reform, Bangkok, pp. 234-265.

Bureau of Savings and Investment Policy, Fiscal Policy Office, Ministry of Finance, Thailand [online; cited August 2007.] Available from URL: http://www.fpo.go.th/fseg/

Burtless, G., 2002, Social Security Privatization and Financial Market Risk: Lessons from U.S. Financial History. In: Social Security Reform in Advanced Countries (eds Ihori T. and Tachibanki T.), pp. 52-80. Routledge, London.

Chaitrong, W., 2008, Govt seeks to level tax playing field. The Nation, Thailand. 24 April 2008 [online; cited July 2008.] Available from URL: http://www.lexisnexis.com/us/lnacademic/

Chaiyasoot, N., 2005, Key Policy Issues in Establishing National Pension Fund (NPF). Organisation of Economic Co-operation and Development, Paris [online; cited August 2007.] Available from URL: http://www.oecd.org/dataoecd/57/7/34745398.pdf

Chantanusornsiri, W., 2006a, Withdrawals Before Age 60 Not Allowed. Bangkok Post, Thailand. 4 January 2006 [online; cited February 2007.] Available from URL: http://www.lexisnexis.com/us/lnacademic/

Chantanusornsiri, W., 2006b, Retirement Age Liable To Be Extended. Bangkok Post, Thailand. 28 August 2006 [online; cited July 2008.] Available from URL: http://www.lexisnexis.com/us/lnacademic/

Feldstein, M. and E. Rangulova, 2001, Individual Risk in an Investment Based Social Security System. American Economic Review, 91, pp. 1116-1125.

Funke, K. and G. Stadtmann, 2004, Operations of a Pension Fund after the Asian Crisis: The Thai Experience. Asian Economic Journal, 18, p. 439-470.

Harris, A. R., J. Sabelhaus and M. Simpson, 2005, Social Security Benefit Uncertainty Under Individual Accounts. Contemporary Economic Policy, 23, pp. 1-16.

Holzmann, R. and R. Hinz, 2005, Old Age Income Support in the $21^{\text {st }}$ Century: An International Perspective on Pension Systems and Reform. World Bank: Washington, DC.

Kanjanaphoomin, N., 2004, Pension Fund, Provident Fund and Social Security System in Thailand. International Conference on Pension in Asia: Incentives, Compliance and Their Role in Retirement, Tokyo.

Kesornsutijarit, J., 2000, Social Security Systems in Thailand: Past experiences, Obstacles, and Ways to Reform. The Third APEC Regional Forum on Pension Fund Reform, Bangkok, pp. 221-233. 
Lee, R. D., M. W. Anderson and S. Tuljapurkar, 2003, Stochastic Forecasts of the Social Security Trust Fund. Center for the Economics and Demography of Aging Papers, University of California, Berkeley.

Lee, R. D. and S. Tuljapurkar, 1998, Stochastic Forecasts for Social Security. In: Frontiers in the Economics of Aging (ed Wise D.), pp. 393-428. University of Chicago Press, Chicago.

National Statistical Office of Thailand [online; cited August 2007.] Available from URL: http://www.nso.go.th

Nichols, O. R., M. D. Clingman and M. P. Glanz, 2001, Internal Real Rates of Return Under the OASDI Program for Hypothetical Workers. Actuarial Note, No. 144, Office of the Chief Actuary, Social Security Administration, Baltimore, MD.

Pai, Y., 2006, Comparing Individual Retirement Accounts in Asia: Singapore, Thailand, Hong Kong, and the PRC. World Bank Social Protection Discussion Paper No. 0609, Washington, DC.

Pfau, W. D., 2003, Essays on Social Security Reform. Unpublished Ph.D. dissertation, Department of Economics, Princeton University.

Population Division of the Department of Economic and Social Affairs of the United Nations Secretariat, 2004, World Population Prospects: The 2004 Revision and World Urbanization Prospects: The 2003 Revision [online; cited April 2007.] Available from URL: http://esa.un.org/unpp

Ryansakul, N., 2000, Pension Fund, Provident Fund and Social Security Systems in Thailand: Past Experiences, Obstacles, and Ways to Reform The Third APEC Regional Forum on Pension Fund Reform, Bangkok, pp. 211-220.

Shiller, R. J., 2005, The Life-Cycle Personal Accounts Proposal for Social Security: A Review, NBER Working Paper Series, No. 11300, National Bureau of Economic Research, Cambridge, MA.

Social Security Office of Thailand, 2005, Annual Report of Social Security Office. Social Security Office, Bangkok.

Steurle, C. E. and J. M. Bakija, 1994, Retooling Social Security for the $21^{\text {st }}$ Century: Right and Wrong Approaches to Reform. The Urban Institute Press: Washington, DC.

Thai Press Reports, 2008, Thailand Financial Ministry Studies Equity and Debt Market Development. 24 April 2008 [online; cited July 2008.] Available from URL: http://www.lexisnexis.com/us/lnacademic/

Whitehouse, E., 2007, Pensions Panorama: Retirement-Income Systems in 53 Countries. World Bank: Washington, DC. 


\section{Table 1}

\section{Asset Allocation of Thailand's Government Pension Fund (as of December 31st)}

\author{
Thai Fixed Income \\ Thai Equity \\ Thai Property \\ Alternative Investments \\ Global Fixed Income \\ Global Equity
}

\begin{tabular}{cccccc}
2001 & 2002 & 2003 & 2004 & 2005 & 2006 \\
\hline $88.0 \%$ & $86.0 \%$ & $80.0 \%$ & $75.7 \%$ & $68.0 \%$ & $71.6 \%$ \\
$7.0 \%$ & $10.0 \%$ & $15.0 \%$ & $15.0 \%$ & $14.0 \%$ & $10.5 \%$ \\
$4.0 \%$ & $3.0 \%$ & $3.0 \%$ & $3.4 \%$ & $3.0 \%$ & $4.3 \%$ \\
$1.0 \%$ & $1.0 \%$ & $2.0 \%$ & $2.7 \%$ & $6.0 \%$ & $4.4 \%$ \\
$0 \%$ & $0 \%$ & $0 \%$ & $0 \%$ & $8.0 \%$ & $5.1 \%$ \\
$0 \%$ & $0 \%$ & $0 \%$ & $3.2 \%$ & $1.0 \%$ & $4.2 \%$
\end{tabular}

Net Assets (billions of baht)

Source: Asset allocations are estimated by the author using Government Pension Fund data (www.gpf.or.th). Total Assets are provided by the Thailand Bureau of Savings and Investment Policy (www.fpo.go.th)

Table 2

Historical Values for Time Series Economic Data

Inflation (Headline CPI)

Interest Rate (one-year fixed deposit)

Real Interest Rate

Average Wage by Industry

Growth Rate of Average Wage

Real Growth Rate of Average Wage

Annual Growth Rate of SET index

Real Growth Rate of SET index

\begin{tabular}{cccc} 
Time Period & $\begin{array}{c}\text { Arithmetic } \\
\text { Mean }\end{array}$ & $\begin{array}{c}\text { Standard } \\
\text { Deviation }\end{array}$ & $\begin{array}{c}\text { Geometric } \\
\text { Mean }\end{array}$ \\
\hline $1979-2005$ & $4.85 \%$ & $4.10 \%$ & $3.49 \%$ \\
& & & \\
$1979-2005$ & $8.15 \%$ & $4.09 \%$ & $6.60 \%$ \\
$1979-2005$ & $3.19 \%$ & $3.89 \%$ & $3.12 \%$ \\
& & & \\
$1989-2005$ & 5,437 baht & 1,570 baht & --- \\
$1990-2005$ & $7.12 \%$ & $8.41 \%$ & $6.82 \%$ \\
$1990-2005$ & $3.06 \%$ & $7.44 \%$ & $2.82 \%$ \\
& & & \\
$1979-2005$ & $11.85 \%$ & $45.07 \%$ & $3.84 \%$ \\
$1979-2005$ & $7.32 \%$ & $44.54 \%$ & $-0.89 \%$
\end{tabular}

Sources: See Methodology section.

Note: For Interest Rate, the year end value is used, and in some years a range of rates is provided in the data. For these cases, we use the middle value of range. 
Table 3

National Pension Fund Defined-Contribution (Pillar 2) Stochastic Distribution of Nest Eggs for Average Earners (Scaled Earnings) Varied by Year of Retirement and Asset Allocation

\begin{tabular}{|c|c|c|c|c|c|c|c|}
\hline & & \multicolumn{6}{|c|}{ Year of Retirement } \\
\hline & & 2014 & 2020 & 2030 & 2040 & 2050 & 2060 \\
\hline \multirow[b]{3}{*}{ Baseline } & Median & 0.43 & 1.08 & 2.24 & 3.28 & 4.00 & 4.21 \\
\hline & Mean & 0.43 & 1.10 & 2.35 & 3.46 & 4.34 & 4.51 \\
\hline & & & & & & & \\
\hline \multirow{2}{*}{ Case } & 5th pct. & 0.38 & 0.90 & 1.69 & 2.26 & 2.60 & 2.69 \\
\hline & 25th pct. & 0.41 & 0.99 & 2.01 & 2.82 & 3.34 & 3.47 \\
\hline \multirow{2}{*}{$\begin{array}{l}15 \% \\
\text { Stocks }\end{array}$} & 75th pct. & 0.45 & 1.18 & 2.58 & 3.97 & 5.02 & 5.25 \\
\hline & 95th pct. & 0.50 & 1.35 & 3.29 & 5.29 & 7.02 & 7.24 \\
\hline \multirow{3}{*}{$\begin{array}{c}85 \% \\
\text { Bonds }\end{array}$} & Prob (Nest Egg > 1) & $0 \%$ & $73.9 \%$ & $100.0 \%$ & $100.0 \%$ & $100.0 \%$ & $100.0 \%$ \\
\hline & Prob (Nest Egg > 4) & $0 \%$ & $0 \%$ & $1.1 \%$ & $23.9 \%$ & $50.1 \%$ & $55.3 \%$ \\
\hline & Prob (Nest Egg > 7) & $0 \%$ & $0 \%$ & $0 \%$ & $0.5 \%$ & $5.1 \%$ & $6.3 \%$ \\
\hline \multirow{9}{*}{$\begin{array}{l}100 \% \\
\text { Stocks }\end{array}$} & Median & 0.41 & 0.95 & 1.73 & 2.32 & 2.73 & 2.80 \\
\hline & Mean & 0.47 & 1.27 & 3.08 & 5.28 & 8.97 & 8.06 \\
\hline & 5th pct. & 0.21 & 0.42 & 0.59 & 0.62 & 0.69 & 0.67 \\
\hline & 25th pct. & 0.31 & 0.67 & 1.05 & 1.31 & 1.40 & 1.38 \\
\hline & 75th pct. & 0.55 & 1.46 & 3.19 & 4.96 & 6.61 & 6.79 \\
\hline & 95th pct. & 0.97 & 3.20 & 9.24 & 18.89 & 25.57 & 27.26 \\
\hline & Prob (Nest Egg > 1) & $4.4 \%$ & $46.6 \%$ & $77.5 \%$ & $84.7 \%$ & $86.5 \%$ & $86.1 \%$ \\
\hline & Prob (Nest Egg $>4$ ) & $0 \%$ & $2.8 \%$ & $18.5 \%$ & $30.7 \%$ & $36.8 \%$ & $39.1 \%$ \\
\hline & Prob (Nest Egg > 7) & $0 \%$ & $0 \%$ & $7.8 \%$ & $17.0 \%$ & $23.4 \%$ & $24.5 \%$ \\
\hline \multirow{5}{*}{$\begin{array}{c}50 \% \\
\text { Stocks }\end{array}$} & Median & 0.42 & 1.07 & 2.17 & 3.19 & 3.87 & 4.11 \\
\hline & Mean & 0.45 & 1.17 & 2.62 & 4.14 & 5.66 & 5.78 \\
\hline & 5th pct. & 0.31 & 0.68 & 1.17 & 1.39 & 1.61 & 1.58 \\
\hline & 25th pct. & 0.37 & 0.88 & 1.64 & 2.26 & 2.59 & 2.69 \\
\hline & 75th pct. & 0.50 & 1.35 & 3.02 & 4.92 & 6.67 & 6.97 \\
\hline \multirow{4}{*}{$\begin{array}{c}50 \% \\
\text { Bonds }\end{array}$} & 95th pct. & 0.67 & 1.99 & 5.62 & 10.00 & 14.01 & 14.43 \\
\hline & Prob (Nest Egg > 1) & $0 \%$ & $58.6 \%$ & $98.4 \%$ & $99.4 \%$ & $99.8 \%$ & $99.7 \%$ \\
\hline & Prob (Nest Egg > 4) & $0 \%$ & $0 \%$ & $12.6 \%$ & $35.6 \%$ & $48.4 \%$ & $51.5 \%$ \\
\hline & Prob (Nest Egg $>7$ ) & $0 \%$ & $0 \%$ & $2.4 \%$ & $12.4 \%$ & $22.5 \%$ & $24.9 \%$ \\
\hline \multirow{9}{*}{$\begin{array}{l}100 \% \\
\text { Bonds }\end{array}$} & Median & 0.43 & 1.06 & 2.21 & 3.13 & 3.81 & 3.94 \\
\hline & Mean & 0.43 & 1.06 & 2.25 & 3.21 & 3.92 & 4.08 \\
\hline & 5th pct. & 0.39 & 0.93 & 1.78 & 2.35 & 2.69 & 2.70 \\
\hline & 25th pct. & 0.41 & 1.00 & 2.01 & 2.79 & 3.26 & 3.37 \\
\hline & 75th pct. & 0.44 & 1.12 & 2.45 & 3.57 & 4.46 & 4.64 \\
\hline & 95th pct. & 0.46 & 1.22 & 2.85 & 4.34 & 5.54 & 5.96 \\
\hline & Prob (Nest Egg $>1)$ & $0 \%$ & $75.7 \%$ & $100.0 \%$ & $100.0 \%$ & $100.0 \%$ & $100.0 \%$ \\
\hline & Prob (Nest Egg $>4)$ & $0 \%$ & $0 \%$ & $0 \%$ & $10.6 \%$ & $40.0 \%$ & $47.1 \%$ \\
\hline & Prob (Nest Egg $>7$ ) & $0 \%$ & $0 \%$ & $0 \%$ & $0 \%$ & $0.7 \%$ & $1.5 \%$ \\
\hline
\end{tabular}


Table 4

National Pension Fund Defined-Contribution (Pillar 2)

Stochastic Distribution of Replacment Rates for Average Earners (Scaled Earnings) Varied by Year of Retirement and Asset Allocation

\begin{tabular}{|c|c|c|c|c|c|c|c|}
\hline & & \multicolumn{6}{|c|}{ Year of Retirement } \\
\hline & & 2014 & 2020 & 2030 & 2040 & 2050 & 2060 \\
\hline \multirow{4}{*}{$\begin{array}{c}\text { Baseline } \\
\text { Case }\end{array}$} & Median & $1.85 \%$ & $4.51 \%$ & $8.88 \%$ & $12.16 \%$ & $13.83 \%$ & $13.64 \%$ \\
\hline & Mean & $1.86 \%$ & $4.58 \%$ & $9.32 \%$ & $12.84 \%$ & $15.01 \%$ & $14.63 \%$ \\
\hline & & & & & & & \\
\hline & 5th pct. & $1.63 \%$ & $3.74 \%$ & $6.71 \%$ & $8.40 \%$ & $9.00 \%$ & $8.71 \%$ \\
\hline \multirow{3}{*}{$\begin{array}{c}15 \% \\
\text { Stocks }\end{array}$} & 25th pct. & $1.76 \%$ & $4.16 \%$ & $7.95 \%$ & $10.46 \%$ & $11.54 \%$ & $11.24 \%$ \\
\hline & 75th pct. & $1.96 \%$ & $4.92 \%$ & $10.23 \%$ & $14.71 \%$ & $17.36 \%$ & $17.06 \%$ \\
\hline & 95th pct. & $2.15 \%$ & $5.65 \%$ & $13.06 \%$ & $19.58 \%$ & $24.28 \%$ & $23.48 \%$ \\
\hline \multirow{3}{*}{$\begin{array}{c}85 \% \\
\text { Bonds }\end{array}$} & Prob (RR > 10\%) & $0 \%$ & $0 \%$ & $28.3 \%$ & $80.0 \%$ & $89.6 \%$ & $87.2 \%$ \\
\hline & Prob (RR > 25\%) & $0 \%$ & $0 \%$ & $0 \%$ & $0.5 \%$ & $4.3 \%$ & $3.3 \%$ \\
\hline & Prob (RR > 50\%) & $0 \%$ & $0 \%$ & $0 \%$ & $0 \%$ & $0 \%$ & $0 \%$ \\
\hline \multirow{9}{*}{$\begin{array}{l}100 \% \\
\text { Stocks }\end{array}$} & Median & $1.76 \%$ & $3.99 \%$ & $6.87 \%$ & $8.59 \%$ & $9.45 \%$ & $9.10 \%$ \\
\hline & Mean & $2.01 \%$ & $5.31 \%$ & $12.19 \%$ & $19.61 \%$ & $31.02 \%$ & $26.14 \%$ \\
\hline & 5th pct. & $0.93 \%$ & $1.78 \%$ & $2.35 \%$ & $2.29 \%$ & $2.39 \%$ & $2.16 \%$ \\
\hline & 25th pct. & $1.32 \%$ & $2.79 \%$ & $4.17 \%$ & $4.85 \%$ & $4.84 \%$ & $4.49 \%$ \\
\hline & 75th pct. & $2.39 \%$ & $6.12 \%$ & $12.64 \%$ & $18.41 \%$ & $22.85 \%$ & $22.01 \%$ \\
\hline & 95th pct. & $4.16 \%$ & $13.41 \%$ & $36.56 \%$ & $70.11 \%$ & $88.45 \%$ & $88.44 \%$ \\
\hline & Prob (RR > 10\%) & $0 \%$ & $9.6 \%$ & $33.0 \%$ & $44.4 \%$ & $48.2 \%$ & $47.4 \%$ \\
\hline & Prob (RR > 25\%) & $0 \%$ & $0.6 \%$ & $9.8 \%$ & $17.9 \%$ & $22.9 \%$ & $21.8 \%$ \\
\hline & Prob (RR > 50\%) & $0 \%$ & $0 \%$ & $3.2 \%$ & $7.8 \%$ & $10.7 \%$ & $10.3 \%$ \\
\hline \multirow{9}{*}{$\begin{array}{c}50 \% \\
\text { Stocks }\end{array}$} & Median & $1.83 \%$ & $4.47 \%$ & $8.61 \%$ & $11.86 \%$ & $13.39 \%$ & $13.34 \%$ \\
\hline & Mean & $1.92 \%$ & $4.88 \%$ & $10.38 \%$ & $15.35 \%$ & $19.59 \%$ & $18.74 \%$ \\
\hline & 5th pct. & $1.32 \%$ & $2.83 \%$ & $4.66 \%$ & $5.18 \%$ & $5.59 \%$ & $5.11 \%$ \\
\hline & 25th pct. & $1.59 \%$ & $3.67 \%$ & $6.48 \%$ & $8.39 \%$ & $8.96 \%$ & $8.71 \%$ \\
\hline & 75th pct. & $2.16 \%$ & $5.64 \%$ & $11.97 \%$ & $18.29 \%$ & $23.06 \%$ & $22.59 \%$ \\
\hline & 95th pct. & $2.88 \%$ & $8.34 \%$ & $22.26 \%$ & $37.09 \%$ & $48.40 \%$ & $46.80 \%$ \\
\hline & Prob (RR > 10\%) & $0 \%$ & $2.2 \%$ & $38.6 \%$ & $61.3 \%$ & $67.3 \%$ & $66.9 \%$ \\
\hline & Prob (RR > 25\%) & $0 \%$ & $0 \%$ & $3.6 \%$ & $13.7 \%$ & $21.2 \%$ & $20.9 \%$ \\
\hline & Prob (RR > 50\%) & $0 \%$ & $0 \%$ & $0 \%$ & $2.1 \%$ & $4.7 \%$ & $4.0 \%$ \\
\hline \multirow{9}{*}{$\begin{array}{l}100 \% \\
\text { Bonds }\end{array}$} & Median & $1.84 \%$ & $4.43 \%$ & $8.74 \%$ & $11.61 \%$ & $13.17 \%$ & $12.78 \%$ \\
\hline & Mean & $1.84 \%$ & $4.45 \%$ & $8.91 \%$ & $11.93 \%$ & $13.55 \%$ & $13.24 \%$ \\
\hline & 5th pct. & $1.70 \%$ & $3.88 \%$ & $7.03 \%$ & $8.71 \%$ & $9.31 \%$ & $8.75 \%$ \\
\hline & 25th pct. & $1.78 \%$ & $4.19 \%$ & $7.94 \%$ & $10.36 \%$ & $11.26 \%$ & $10.93 \%$ \\
\hline & 75th pct. & $1.89 \%$ & $4.68 \%$ & $9.71 \%$ & $13.24 \%$ & $15.43 \%$ & $15.05 \%$ \\
\hline & 95th pct. & $1.98 \%$ & $5.12 \%$ & $11.30 \%$ & $16.12 \%$ & $19.18 \%$ & $19.37 \%$ \\
\hline & Prob $(R R>10 \%)$ & $0 \%$ & $0 \%$ & $18.6 \%$ & $80.5 \%$ & $88.8 \%$ & $86.3 \%$ \\
\hline & Prob (RR > 25\%) & $0 \%$ & $0 \%$ & $0 \%$ & $0 \%$ & $0 \%$ & $0.6 \%$ \\
\hline & Prob (RR > 50\%) & $0 \%$ & $0 \%$ & $0 \%$ & $0 \%$ & $0 \%$ & $0 \%$ \\
\hline
\end{tabular}


Table 5

Total Pension (OAPF + NPF)

Stochastic Distribution of Replacment Rates for Average Earners (Scaled Earnings) Varied by Year of Retirement and Asset Allocation

\begin{tabular}{|c|c|c|c|c|c|c|c|}
\hline & & \multicolumn{6}{|c|}{ Year of Retirement } \\
\hline & & 2014 & 2020 & 2030 & 2040 & 2050 & 2060 \\
\hline \multirow{4}{*}{$\begin{array}{c}\text { Baseline } \\
\text { Case }\end{array}$} & Median & $23.35 \%$ & $35.01 \%$ & $54.38 \%$ & $69.66 \%$ & $71.33 \%$ & $71.14 \%$ \\
\hline & Mean & $23.36 \%$ & $35.08 \%$ & $54.82 \%$ & $70.34 \%$ & $72.51 \%$ & $72.13 \%$ \\
\hline & & & & & & & \\
\hline & 5th pct. & $23.13 \%$ & $34.24 \%$ & $52.21 \%$ & $65.90 \%$ & $66.50 \%$ & $66.21 \%$ \\
\hline \multirow{3}{*}{$\begin{array}{l}15 \% \\
\text { Stocks }\end{array}$} & 25th pct. & $23.26 \%$ & $34.66 \%$ & $53.45 \%$ & $67.96 \%$ & $69.04 \%$ & $68.74 \%$ \\
\hline & 75th pct. & $23.46 \%$ & $35.42 \%$ & $55.73 \%$ & $72.21 \%$ & $74.86 \%$ & $74.56 \%$ \\
\hline & 95th pct. & $23.65 \%$ & $36.15 \%$ & $58.56 \%$ & $77.08 \%$ & $81.78 \%$ & $80.98 \%$ \\
\hline \multirow{3}{*}{$\begin{array}{c}85 \% \\
\text { Bonds }\end{array}$} & Prob (RR > 60\%) & $0 \%$ & $0 \%$ & $2.1 \%$ & $100.0 \%$ & $100.0 \%$ & $100.0 \%$ \\
\hline & Prob (RR > 70\%) & $0 \%$ & $0 \%$ & $0 \%$ & $45.7 \%$ & $64.1 \%$ & $61.1 \%$ \\
\hline & Prob (RR > 80\%) & $0 \%$ & $0 \%$ & $0 \%$ & $1.3 \%$ & $8.3 \%$ & $6.6 \%$ \\
\hline \multirow{9}{*}{$\begin{array}{l}100 \% \\
\text { Stocks }\end{array}$} & Median & $23.26 \%$ & $34.49 \%$ & $52.37 \%$ & $66.09 \%$ & $66.95 \%$ & $66.60 \%$ \\
\hline & Mean & $23.51 \%$ & $35.81 \%$ & $57.69 \%$ & $77.11 \%$ & $88.52 \%$ & $83.64 \%$ \\
\hline & 5th pct. & $22.43 \%$ & $32.28 \%$ & $47.85 \%$ & $59.79 \%$ & $59.89 \%$ & $59.66 \%$ \\
\hline & 25th pct. & $22.82 \%$ & $33.29 \%$ & $49.67 \%$ & $62.35 \%$ & $62.34 \%$ & $61.99 \%$ \\
\hline & 75th pct. & $23.89 \%$ & $36.62 \%$ & $58.14 \%$ & $75.91 \%$ & $80.35 \%$ & $79.51 \%$ \\
\hline & 95th pct. & $25.66 \%$ & $43.91 \%$ & $82.06 \%$ & $127.61 \%$ & $145.95 \%$ & $145.94 \%$ \\
\hline & Prob (RR > 60\%) & $0 \%$ & $0 \%$ & $20.5 \%$ & $93.8 \%$ & $94.2 \%$ & $92.5 \%$ \\
\hline & Prob (RR > 70\%) & $0 \%$ & $0 \%$ & $10.0 \%$ & $36.6 \%$ & $40.3 \%$ & $40.1 \%$ \\
\hline & Prob (RR > 80\%) & $0 \%$ & $0 \%$ & $5.5 \%$ & $20.2 \%$ & $25.3 \%$ & $24.6 \%$ \\
\hline \multirow{9}{*}{$\begin{array}{c}50 \% \\
\text { Stocks }\end{array}$} & Median & $23.33 \%$ & $34.97 \%$ & $54.11 \%$ & $69.36 \%$ & $70.89 \%$ & $70.84 \%$ \\
\hline & Mean & $23.42 \%$ & $35.38 \%$ & $55.88 \%$ & $72.85 \%$ & $77.09 \%$ & $76.24 \%$ \\
\hline & 5th pct. & $22.82 \%$ & $33.33 \%$ & $50.16 \%$ & $62.68 \%$ & $63.09 \%$ & $62.61 \%$ \\
\hline & 25th pct. & $23.09 \%$ & $34.17 \%$ & $51.98 \%$ & $65.89 \%$ & $66.46 \%$ & $66.21 \%$ \\
\hline & 75th pct. & $23.66 \%$ & $36.14 \%$ & $57.47 \%$ & $75.79 \%$ & $80.56 \%$ & $80.09 \%$ \\
\hline & 95th pct. & $24.38 \%$ & $38.84 \%$ & $67.76 \%$ & $94.59 \%$ & $105.90 \%$ & $104.30 \%$ \\
\hline & Prob (RR > 60\%) & $0 \%$ & $0 \%$ & $16.1 \%$ & $100.0 \%$ & $100.0 \%$ & $99.9 \%$ \\
\hline & Prob (RR > 70\%) & $0 \%$ & $0 \%$ & $4.0 \%$ & $46.2 \%$ & $54.0 \%$ & $53.7 \%$ \\
\hline & Prob (RR > 80\%) & $0 \%$ & $0 \%$ & $1.2 \%$ & $16.7 \%$ & $25.8 \%$ & $25.1 \%$ \\
\hline \multirow{9}{*}{$\begin{array}{l}100 \% \\
\text { Bonds }\end{array}$} & Median & $23.34 \%$ & $34.93 \%$ & $54.24 \%$ & $69.11 \%$ & $70.67 \%$ & $70.28 \%$ \\
\hline & Mean & $23.34 \%$ & $34.95 \%$ & $54.41 \%$ & $69.43 \%$ & $71.05 \%$ & $70.74 \%$ \\
\hline & 5th pct. & $23.20 \%$ & $34.38 \%$ & $52.53 \%$ & $66.21 \%$ & $66.81 \%$ & $66.25 \%$ \\
\hline & 25th pct. & $23.28 \%$ & $34.69 \%$ & $53.44 \%$ & $67.86 \%$ & $68.76 \%$ & $68.43 \%$ \\
\hline & 75th pct. & $23.39 \%$ & $35.18 \%$ & $55.21 \%$ & $70.74 \%$ & $72.93 \%$ & $72.55 \%$ \\
\hline & 95th pct. & $23.48 \%$ & $35.62 \%$ & $56.80 \%$ & $73.62 \%$ & $76.68 \%$ & $76.87 \%$ \\
\hline & Prob $(R R>60 \%)$ & $0 \%$ & $0 \%$ & $0 \%$ & $100.0 \%$ & $100.0 \%$ & $100.0 \%$ \\
\hline & Prob (RR > 70\%) & $0 \%$ & $0 \%$ & $0 \%$ & $35.0 \%$ & $60.1 \%$ & $53.4 \%$ \\
\hline & Prob (RR > 80\%) & $0 \%$ & $0 \%$ & $0 \%$ & $0 \%$ & $1.4 \%$ & $1.6 \%$ \\
\hline
\end{tabular}


Figure 1

Scaled Earnings: Mean Wage by Age as a Percentage of Thailand's Average Wage

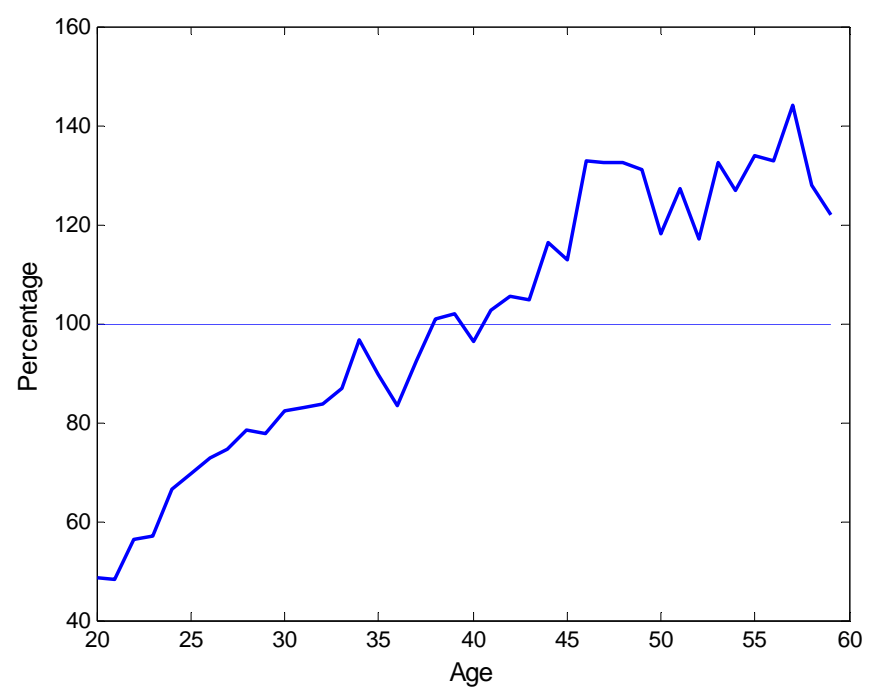

Source: Authors’ calculations from 2002 Socioeconomic Survey of Thailand

Figure 2

National Pension Fund Defined-Contribution (Pillar 2)

Nest-Egg Ratio Distribution for Average Earners (Scaled Earnings)

Investment Portfolio: 15\% Stocks, 85\% Bonds

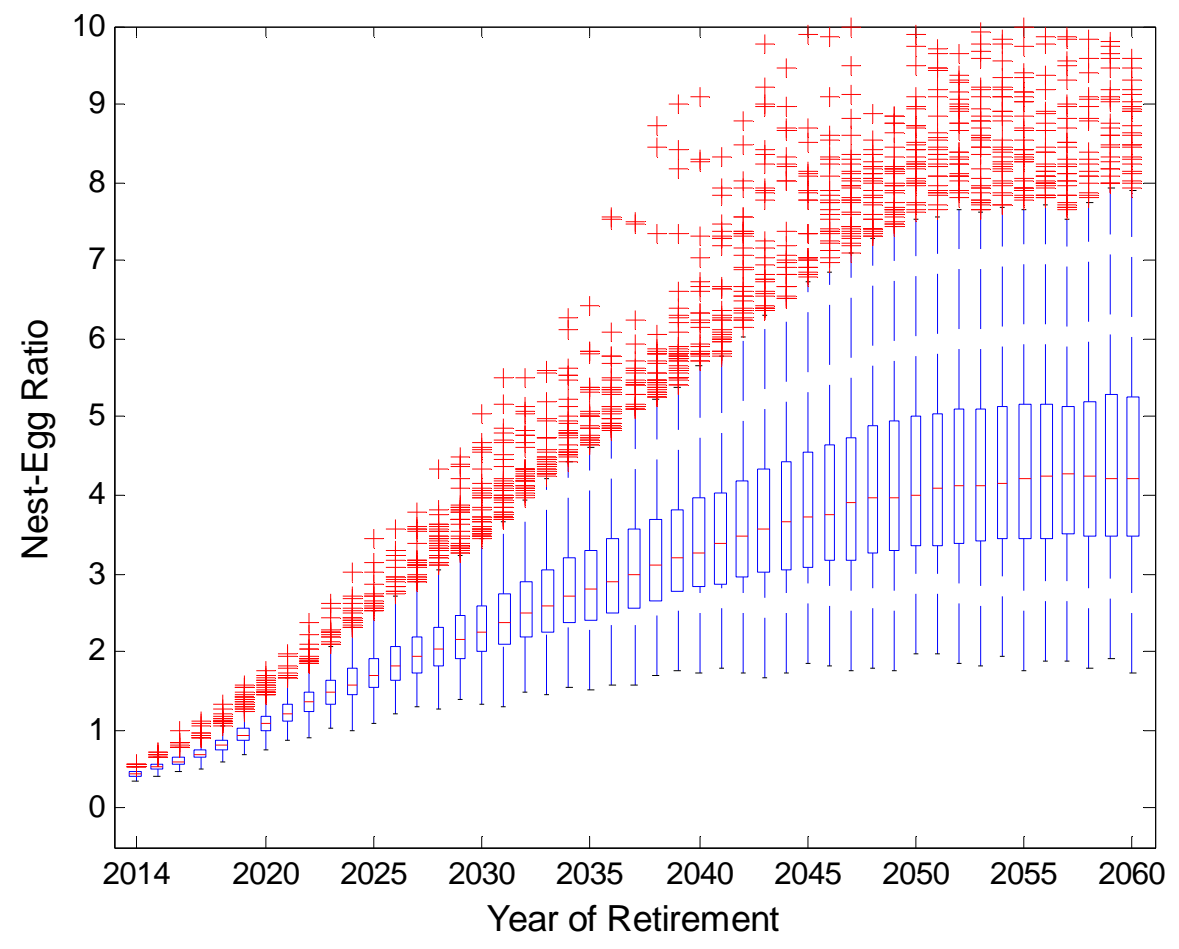

